Supporting Information

\title{
Ionic Organocatalyst with Urea Anion and Tetra-n-butyl Ammonium Cation for Rapid, Selective, and Versatile Ring-Opening Polymerization of Lactide
}

\author{
Zhuolun Jiang, Junpeng Zhao*, and Guangzhao Zhang \\ Faculty of Materials Science and Engineering, South China University of Technology, \\ Guangzhou 510640, People's Republic of China
}

\section{Experimental Section}

Materials. All chemicals were purchased from Aladdin unless otherwise specified. $\varepsilon$-Caprolactone (CL; 99\%), $\delta$-valerolactone (VL; 98\%), dichloromethane (DCM; 99.5\%), and toluene (Guangzhou Chemical Reagent, AR) were dried by stirring with calcium hydride overnight and vacuum-distilled. Tetrahydrofuran (THF; 99\%) was dried successively by

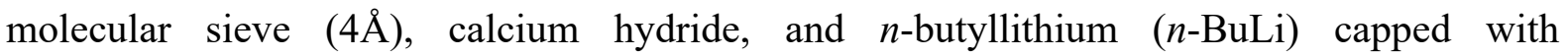
1,1-diphenylethylene before vacuum-distilled. rac-Lacide and L-lactide (LA and LLA; Jinan Daigang Biomaterial Co., Ltd., 99.5\%) were recrystallized from distilled ethyl acetate (99\%) and dried by azeotropic distillation of purified THF. 1-Naphthalenemethanol (NtA; 98\%), 1,1,1-tris(hydroxymethyl)propane (TP; Energy Chemical, 98\%) and 1,3-diphenylthiourea (TU; TCI, 98\%) were vacuum-dried prior to use. Chloroform (Guangzhou Chemical Reagent, 
AR), methanol (AR), dimethyl sulfoxide (DMSO; Energy Chemical, 99.7\%, extra dry, stored with molecular sieve), tetra- $n$-butylammonium hydroxide (TBOH; $0.8 \mathrm{M}$ in methanol), 5-norbornene-2-methanol ( $\mathrm{NbA} ; 99 \%)$, and acetic acid $(\mathrm{AcOH} ; \mathrm{AR})$ were used as received. 1,3-Bis-[3,5-bis(trifluoromethyl)phenyl]urea $\quad(\mathrm{U} 1), \quad$ 1-[3,5-bis(trifluoromethyl)phenyl]-3phenylurea (U2), 1-[3,5-bis(trifluoromethyl)phenyl]-3-methylphenylurea (U3) were synthesized by reaction between the corresponding primary/secondary amine and isocyanate. Instrumentation. Size exclusion chromatography (SEC) coupled with RI and UV detectors was conducted in THF at $35^{\circ} \mathrm{C}$ using two identical PLgel columns (5 $\mu \mathrm{m}$, MIXED-C) at a

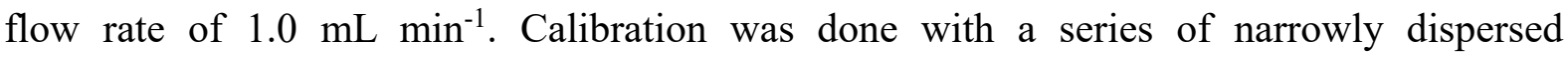
polystyrene standards to obtain apparent number-average molar mass $\left(M_{\mathrm{n}, \mathrm{SEC}}\right)$ and molar mass distribution ( $\oslash_{\mathrm{M}}$; or dispersity) of the polymers. NMR spectra were recorded at room temperature (RT) on a Bruker AV600 NMR spectrometer using $\mathrm{CDCl}_{3}$ or DMSO- $d_{6}$ as the solvent with tetramethylsilane as the internal standard. ${ }^{1} \mathrm{H}$ NMR spectrum was used to calculate the monomer conversion by comparison of the integrals of characteristic signals from the remaining monomer and the corresponding signals from the polymer. Number-average molar mass of the isolated (co)polymer $\left(M_{\mathrm{n}, \mathrm{NMR}}\right)$ were calculated from ${ }^{1} \mathrm{H}$ NMR spectrum through comparison of signal integrals from the end group (e.g. methylene or methine protons next to the terminal hydroxyls) and polymer main body (e.g. methylene or methine protons next to the ester groups). Homonuclear decoupled ${ }^{1} \mathrm{H}$ NMR spectrum was used to calculate the isotacticity of poly(L-lactide) samples determined by the proportion of non-racemic integrals (methine proton, $\delta / \mathrm{ppm}=5.18 \sim 5.12$ ). Matrix assisted laser 
desorption/ionization time-of-flight mass spectrometry (MALDI-TOF MS) measurements were performed on a Bruker Autoflex III Smartbeam MALDI-TOF mass spectrometer. Samples were dissolved in THF $\left(10 \mathrm{mg} \mathrm{mL}^{-1}\right)$ and mixed with a solution of sodium trifluoroacetate (NaTFA) in THF $\left(10 \mathrm{mg} \mathrm{mL}^{-1}\right)$ in a volume ratio of $5: 1$. This solution was then mixed with a THF solution of matrix (2,5-dihdroxybenzoic acid, $\left.20 \mathrm{mg} \mathrm{mL}^{-1}\right)$ in a volume ratio of $1: 10$. Then, $0.4 \mu \mathrm{L}$ of the final solution was spotted on the target plate (dried-droplet method). The reflective positive ion mode was used to acquire the mass spectra of the samples. Calibration was done externally with poly(methyl methacrylate) standards using the nearest neighbor positions. Differential scanning calorimetry (DSC) measurement was performed on a NETZSCH DSC204F1 system in a nitrogen flow. The sample was quickly heated to $210{ }^{\circ} \mathrm{C}$, kept at this temperature for 10 min to remove thermal history, cooled to $30{ }^{\circ} \mathrm{C}$ at a cooling rate of $10{ }^{\circ} \mathrm{C} \mathrm{min}-1$, and then heated again to $210{ }^{\circ} \mathrm{C}$ at a heating rate of $10{ }^{\circ} \mathrm{C} \min ^{-1}$.

Preparation of Ureas. Ureas that are not commercially available were synthesized by reaction of the corresponding amine (excess) and isocyanate. A typical procedure for U1 is as follows. $0.765 \mathrm{~g}$ of 3,5-bis(trifluoromethyl)phenyl isocyanate $(3.0 \mathrm{mmol}), 1.031 \mathrm{~g}$ of 3,5-bis(trifluoromethyl)phenylamine $(4.5 \mathrm{mmol})$, and $20 \mathrm{~mL}$ toluene were added in a pre-dried $50 \mathrm{~mL}$ Schlenk flask and stirred at RT for 6 hours. Then toluene was removed by rotary evaporation and the crude product was washed 3 times with toluene. The white solid product was collected by filtration and dried under vacuum at $40{ }^{\circ} \mathrm{C}$ overnight. Yield $=1.06 \mathrm{~g}$ $(73 \%)$. 
The synthesis of thioureas followed a similar procedure except that DCM was used as the solvent and the crude product was washed by chloroform.

Preparation of Ionic Organocatalysts. The ionic organocatalysts (TUA/UA) used in this study were prepared by reaction (dehydration) of the corresponding thiourea/urea (excess) and $\mathrm{TBOH}$. A typical procedure for UA1 is as follows. $1.25 \mathrm{~mL}$ TBOH solution $(1.0 \mathrm{mmol})$ and $1.21 \mathrm{~g} \mathrm{U1}(2.5 \mathrm{mmol})$ were mixed with $15 \mathrm{~mL}$ of THF in a $50 \mathrm{~mL}$ round-bottom Schlenk flask. The mixture was stirred at $40{ }^{\circ} \mathrm{C}$ for $1 \mathrm{~h}$ followed by slow removal of THF by vacuum distillation. The remaining solid was heated at $80{ }^{\circ} \mathrm{C}$ under vacuum with constant pumping of an oil pump for $8 \mathrm{~h}$. Then $5 \mathrm{~mL}$ of DMSO and $20 \mathrm{~mL}$ of THF were added to afford a homogeneous catalyst solution with the concentration of urea anion being $0.04 \mathrm{~mol} \mathrm{~L}^{-1}$.

\section{Polymerization Procedures.}

Polymerization of $L A / L L A$. A typical procedure for U1LA3 (Table 1) is given as follows. In a glovebox, a pre-dried $50 \mathrm{~mL}$ Schlenk flask was charged with $0.26 \mathrm{~mL}$ of UA1 solution $(0.01$ mmol of UA1 and $0.015 \mathrm{mmol}$ of $\mathrm{U} 1), 1.58 \mathrm{mg}$ of NtA $(0.01 \mathrm{mmol})$ and $0.8 \mathrm{~mL}$ of DCM. The mixture was stirred until NtA was fully dissolved. Then a solution of $0.29 \mathrm{~g}$ LA (2.0 $\mathrm{mmol})$ in $1.8 \mathrm{~mL}$ of DCM was quickly injected in the reaction flask ([LA $\left.]_{0}=0.70 \mathrm{~mol} \mathrm{~L}^{-1}\right)$. The solution was quickly stirred at RT for $1 \mathrm{~min}$. Half of the solution was withdrawn and mixed with $c a .0 .1 \mathrm{~mL}$ of $\mathrm{AcOH}$ to quench the reaction (the other half was left in the reaction flask for an extended reaction time of $5 \mathrm{~min}$ ). A small amount of the crude product was withdrawn for ${ }^{1} \mathrm{H}$ NMR and SEC analysis. The polymer was precipitated in methanol and dried in a vacuum. Conv. $(\mathrm{LA})=98 \%, M_{\mathrm{n}, \mathrm{th}}=28.2 \mathrm{~kg} \mathrm{~mol}^{-1} \cdot M_{\mathrm{n}, \mathrm{SEC}}=33.6 \mathrm{~kg} \mathrm{~mol}^{-1}, \bigoplus_{\mathrm{M}}=$ 
1.10. ${ }^{1} \mathrm{H}$ NMR $\left(600 \mathrm{MHz}, \mathrm{CDCl}_{3}\right): \delta / \mathrm{ppm}=8.05 \sim 6.96$ (aromatic protons of NtA-derived end

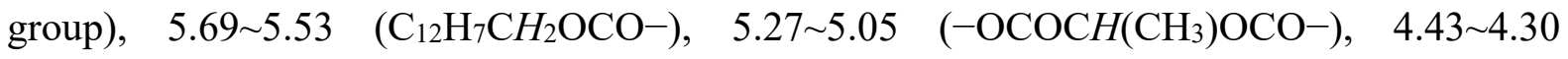
$\left(-\mathrm{OCOCH}\left(\mathrm{CH}_{3}\right) \mathrm{OH}\right), 1.76 \sim 0.74\left(-\mathrm{OCOCH}\left(\mathrm{CH}_{3}\right)-\right), M_{\mathrm{n}, \mathrm{NMR}}=25.4 \mathrm{~kg} \mathrm{~mol}^{-1}$.

Polymerization of LLA followed the same procedure. Typically, U1LLA1 is synthesized by use of $25.0 \mu \mathrm{L}$ of UA1 solution $(0.001 \mathrm{mmol}$ of UA1 and $0.0015 \mathrm{mmol}$ of U1), $6.0 \mu \mathrm{L}$ of $\mathrm{NbA}(6.2 \mathrm{mg}, 0.05 \mathrm{mmol}), 0.29 \mathrm{~g}$ of LLA $(2.0 \mathrm{mmol})$ and $2.9 \mathrm{~mL}$ of DCM. Conv.(LLA) $=$ $95 \%, M_{\mathrm{n}, \mathrm{th}}=5.5 \mathrm{~kg} \mathrm{~mol}^{-1} \cdot M_{\mathrm{n}, \mathrm{SEC}}=8.6 \mathrm{~kg} \mathrm{~mol}^{-1}, \bigoplus_{\mathrm{M}}=1.13 .{ }^{1} \mathrm{H} \mathrm{NMR}\left(600 \mathrm{MHz}, \mathrm{CDCl}_{3}\right):$ $\delta / \mathrm{ppm}=6.20 \sim 5.85 \quad(-\mathrm{CH}=\mathrm{CH}-\quad$ of $\mathrm{NbA}$-derived end group $), \quad 5.25 \sim 5.08$ $\left(-\mathrm{OCOCH}\left(\mathrm{CH}_{3}\right) \mathrm{OCO}^{-}\right), 4.38 \sim 4.32\left(-\mathrm{OCOCH}\left(\mathrm{CH}_{3}\right) \mathrm{OH}\right), \quad 1.61 \sim 1.49\left(-\mathrm{OCOCH}\left(\mathrm{CH}_{3}\right)^{-}\right)$, $M_{\mathrm{n}, \mathrm{NMR}}=4.6 \mathrm{~kg} \mathrm{~mol}^{-1}$.

Block Copolymerization of VL and LLA. The procedure for U1VL-LLA (Table S1) is given as follows. In the glovebox, a pre-dried $50 \mathrm{~mL}$ Schlenk flask was charged with $0.16 \mathrm{~mL}$ of UA1 solution $(0.0065 \mathrm{mmol}$ of UA1 and $0.01 \mathrm{mmol}$ of $\mathrm{U} 1), 3.9 \mu \mathrm{L}$ of $\mathrm{NbA}(0.033 \mathrm{mmol})$ and 0.63 $\mathrm{mL}$ of THF. Then $0.29 \mathrm{~mL}$ of VL $(0.33 \mathrm{~g}, 3.25 \mathrm{mmol})$ was injected in the flask and the mixture was stirred for $105 \mathrm{~min}\left([\mathrm{VL}]_{0}=3.0 \mathrm{~mol} \mathrm{~L}^{-1}\right)$. A $0.1 \mathrm{~mL}$ aliquot was withdrawn, quenched with $0.05 \mathrm{~mL}$ of $\mathrm{AcOH}$ and used for ${ }^{1} \mathrm{H}$ NMR and SEC analysis. Conv.(VL) $=90 \%$, $M_{\mathrm{n}, \mathrm{th}}(\mathrm{VL})=9.0 \mathrm{~kg} \mathrm{~mol}^{-1} \cdot M_{\mathrm{n}, \mathrm{SEC}}(\mathrm{VL})=14.4 \mathrm{~kg} \mathrm{~mol}^{-1}, \bigoplus_{\mathrm{M}}(\mathrm{PVL})=1.13$.

Subsequently, the reaction mixture was diluted with $1.6 \mathrm{~mL}$ of DCM. Then a solution of $0.468 \mathrm{~g}$ of LLA $(3.25 \mathrm{mmol})$ in $2.3 \mathrm{~mL}$ of DCM was quickly injected in the reaction flask $\left([\mathrm{LLA}]_{0}=0.70 \mathrm{~mol} \mathrm{~L}^{-1}\right)$. After $5 \mathrm{~min}, c a .0 .1 \mathrm{~mL}$ of AcOH was added to quench the reaction. The copolymer was precipitated in methanol and dried in a vacuum. $\Delta$ Conv. $(\mathrm{VL})=0$; 
Conv. $($ LLA $)=84 \%, M_{\mathrm{n}, \mathrm{th}}(\mathrm{PVL}-b-\mathrm{PLLA})=21.1 \mathrm{~kg} \mathrm{~mol}^{-1} \cdot M_{\mathrm{n}, \mathrm{SEC}}(\mathrm{PVL}-b-\mathrm{PLLA})=28.1 \mathrm{~kg}$ $\mathrm{mol}^{-1}, \bigoplus_{\mathrm{M}}(\mathrm{PVL}-b-\mathrm{PLLA})=1.15 .{ }^{1} \mathrm{H}$ NMR $\left(600 \mathrm{MHz}, \mathrm{CDCl}_{3}\right): \delta / \mathrm{ppm}=6.17 \sim 5.91$ ( $-\mathrm{CH}=\mathrm{CH}-$ of $\mathrm{NbA}$-derived end group), 5.24 5.09 (-OCOCH(CH3)OCO-$), 4.38 \sim 4.32$ $\left(-{ }^{-} \mathrm{OCOCH}\left(\mathrm{CH}_{3}\right) \mathrm{OH}\right), \quad 4.11 \sim 4.03 \quad\left(-\mathrm{OCOCH}_{2} \mathrm{CH}_{2} \mathrm{CH}_{2} \mathrm{CH}_{2} \mathrm{OCO}^{-}\right), \quad 2.36 \sim 2.29$ $\left(-\mathrm{OCOCH}_{2} \mathrm{CH}_{2} \mathrm{CH}_{2} \mathrm{CH}_{2} \mathrm{O}^{-}\right), 1.73 \sim 1.52\left(-\mathrm{OCOCH}_{2} \mathrm{CH}_{2} \mathrm{CH}_{2} \mathrm{CH}_{2} \mathrm{O}^{-}\right)$\& $\left(-\mathrm{OCOCH}\left(\mathrm{CH}_{3}\right)^{-}\right)$, $M_{\mathrm{n}, \mathrm{NMR}}=21.8 \mathrm{~kg} \mathrm{~mol}^{-1}$.

Block Copolymerization of CL and LLA. The procedure for U1CL-LLA (Table S1) is given as follows. In the glovebox, a pre-dried $50 \mathrm{~mL}$ Schlenk flask was charged with $0.41 \mathrm{~mL}$ of UA1 solution $(0.016 \mathrm{mmol}$ of UA1 and $0.024 \mathrm{mmol}$ of U1), $3.9 \mathrm{mg}$ of TP $(0.027 \mathrm{mmol})$ and 0.37 $\mathrm{mL}$ of THF. Then $0.36 \mathrm{~mL}$ of $\mathrm{CL}(0.37 \mathrm{~g}, 3.25 \mathrm{mmol})$ was injected in the flask and the mixture was stirred for $2.5 \mathrm{~h}\left([\mathrm{CL}]_{0}=3.0 \mathrm{~mol} \mathrm{~L}^{-1}\right)$. A $0.1 \mathrm{~mL}$ aliquot was withdrawn, quenched with $0.05 \mathrm{~mL}$ of $\mathrm{AcOH}$ and used for ${ }^{1} \mathrm{H}$ NMR and SEC analysis. Conv.(CL) $=92 \%$, $M_{\mathrm{n}, \mathrm{th}}(\mathrm{CL})=12.6 \mathrm{~kg} \mathrm{~mol}^{-1} . M_{\mathrm{n}, \mathrm{SEC}}(\mathrm{CL})=21.4 \mathrm{~kg} \mathrm{~mol}^{-1}, \bigoplus_{\mathrm{M}}(\mathrm{PCL})=1.16$.

Subsequently, $1.6 \mathrm{~mL}$ of DCM was added in the reaction flask and the mixture was stirred for $3 \mathrm{~min}$. Then a solution of $0.468 \mathrm{~g}$ LLA $(3.25 \mathrm{mmol})$ in $2.3 \mathrm{~mL}$ of DCM was quickly injected in the reaction flask $\left([\mathrm{LLA}]_{0}=0.70 \mathrm{~mol} \mathrm{~L}^{-1}\right)$. After $1 \mathrm{~min}, c a .0 .1 \mathrm{~mL}$ of $\mathrm{AcOH}$ was added to quench the reaction. The copolymer was precipitated in methanol and dried in a vacuum. $\Delta$ Conv. $(\mathrm{CL})=0 ;$ Conv.(LLA) $=97 \%, M \mathrm{n}, \mathrm{th}(3-$ arm PCL- $b-$ PLLA $)=29.4 \mathrm{~kg} \mathrm{~mol}{ }^{-1}$. $M_{\mathrm{n}, \mathrm{SEC}}(3$-arm PCL- $b$-PLLA $)=45.3 \mathrm{~kg} \mathrm{~mol}^{-1}, \bigoplus_{\mathrm{M}}(3$-arm PCL- $b$-PLLA $)=1.14 .{ }^{1} \mathrm{H}$ NMR $(600$

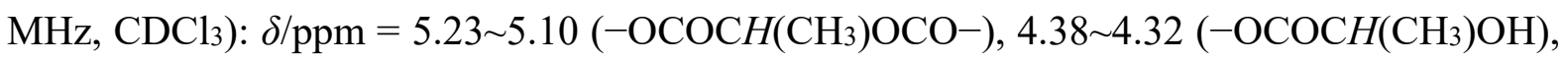
4.10 4.03 (- $\left.\mathrm{OCOCH}_{2} \mathrm{CH}_{2} \mathrm{CH}_{2} \mathrm{CH}_{2} \mathrm{CH}_{2} \mathrm{OCO}-\right)$, 2.33 2.27 (- $\left.\mathrm{OCOCH}_{2} \mathrm{CH}_{2} \mathrm{CH}_{2} \mathrm{CH}_{2} \mathrm{CH}_{2} \mathrm{O}-\right)$, 
$1.68 \sim 1.61 \quad\left(-\mathrm{OCOCH}_{2} \mathrm{CH}_{2} \mathrm{CH}_{2} \mathrm{CH}_{2} \mathrm{CH}_{2} \mathrm{O}^{-}\right), \quad 1.60 \sim 1.55 \quad\left(-\mathrm{OCOCH}\left(\mathrm{CH}_{3}\right)^{-}\right), \quad 1.43 \sim 1.34$ $\left(-\mathrm{OCOCH}_{2} \mathrm{CH}_{2} \mathrm{CH}_{2} \mathrm{CH}_{2} \mathrm{CH}_{2} \mathrm{O}^{-}\right), M_{\mathrm{n}, \mathrm{NMR}}=30.5 \mathrm{~kg} \mathrm{~mol}^{-1}$.

Polymerization LLA from PS-OH Macroinitiator. Hydroxyl-terminated polystyrene (PS-OH) was synthesized by sec-butyllithium-initiated anionic polymerization of styrene followed by end-capping with ethylene oxide. ${ }^{36} M_{\mathrm{n}, \mathrm{SEC}}(\mathrm{PS}-\mathrm{OH})=10.0 \mathrm{~kg} \mathrm{~mol}^{-1}, \bigoplus_{\mathrm{M}}=1.04$.

The procedure for U1LLA9 (Table S1) is given as follows. In a glovebox, a pre-dried $50 \mathrm{~mL}$ Schlenk flask was charged with $0.12 \mathrm{~mL}$ of UA1 solution $(0.0047 \mathrm{mmol}$ of UA1 and 0.007 mmol of U1), $0.234 \mathrm{~g}$ of PS-OH $\left(0.0234 \mathrm{mmol}\right.$; pre-dried in vacuum at $40{ }^{\circ} \mathrm{C}$ overnight $)$, and $2.3 \mathrm{~mL}$ of THF. The mixture was stirred at RT for $10 \mathrm{~min}$ until PS-OH was dissolved completely. Then a solution of $0.47 \mathrm{~g}$ LLA $(3.25 \mathrm{mmol})$ in $2.3 \mathrm{~mL}$ of DCM was quickly injected in the reaction flask $\left([\mathrm{LLA}]_{0}=0.70 \mathrm{~mol} \mathrm{~L}^{-1}\right)$. The solution was stirred at RT for 5 min and the reaction was quenched by addition of $c a .0 .1 \mathrm{~mL}$ of $\mathrm{AcOH}$. The copolymer was precipitated in methanol and dried in a vacuum. Conv.(LLA) $=97 \%, M_{\mathrm{n}, \mathrm{th}}=30.0 \mathrm{~kg} \mathrm{~mol}^{-1}$. $M_{\mathrm{n}, \mathrm{SEC}}=41.9 \mathrm{~kg} \mathrm{~mol}^{-1}, \bigoplus_{\mathrm{M}}=1.07 .{ }^{1} \mathrm{H} \mathrm{NMR}\left(600 \mathrm{MHz}, \mathrm{CDCl}_{3}\right): \delta / \mathrm{ppm}=7.22 \sim 6.31$

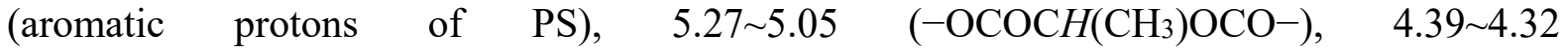
$\left(-\mathrm{OCOCH}\left(\mathrm{CH}_{3}\right) \mathrm{OH}\right), \quad 3.78 \sim 3.72 \quad\left(-\mathrm{CH}_{2} \mathrm{CH}_{2} \mathrm{OCO}-\right), \quad 2.03 \sim 1.22 \quad\left(-\mathrm{CH}_{2} \mathrm{CH}\left(\mathrm{C}_{6} \mathrm{H}_{5}\right)^{-}\right) \quad \&$ $\left(-\mathrm{OCOCH}\left(\mathrm{CH}_{3}\right)^{-}\right), M_{\mathrm{n}, \mathrm{NMR}}=26.2 \mathrm{~kg} \mathrm{~mol}^{-1}$. 


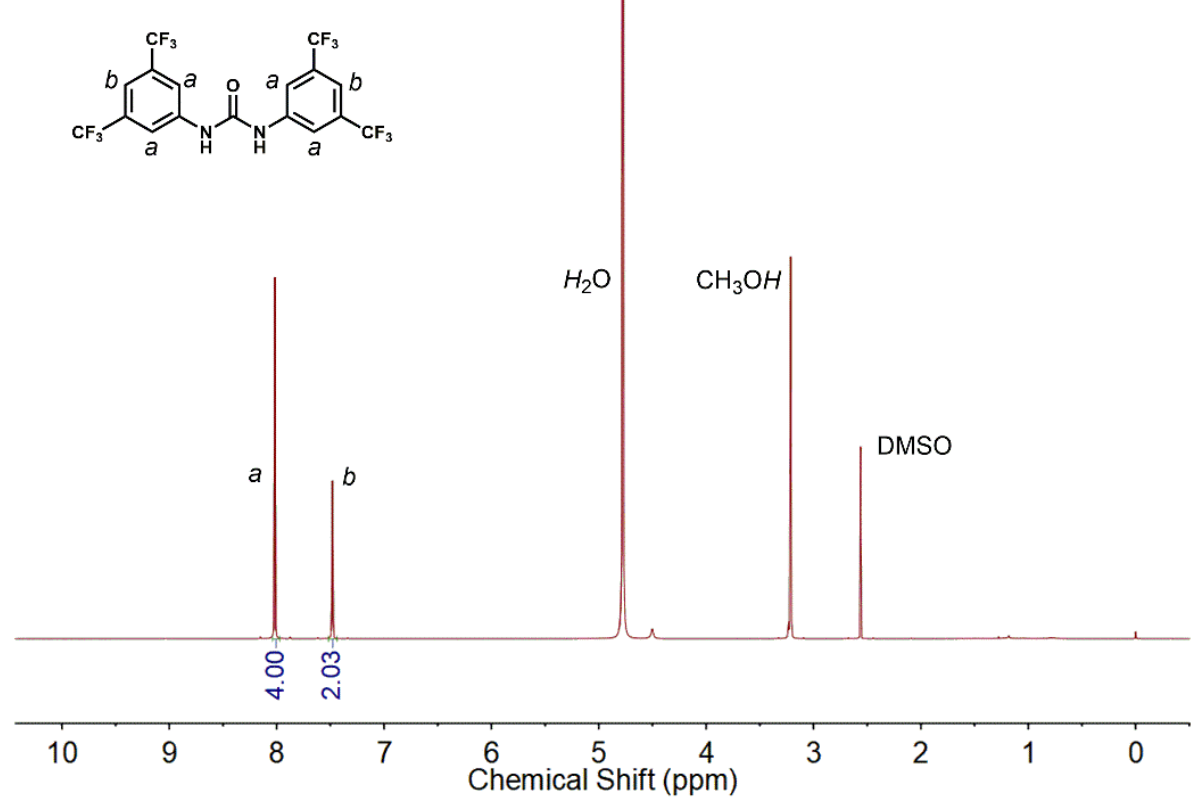

Figure S1. ${ }^{1} \mathrm{H} \mathrm{NMR}\left(\mathrm{CD}_{3} \mathrm{OD}\right)$ of $\mathrm{U} 1: \delta 8.02(a, 4 \mathrm{H}, \mathrm{s}), 7.48(b, 2 \mathrm{H}, \mathrm{s})$.

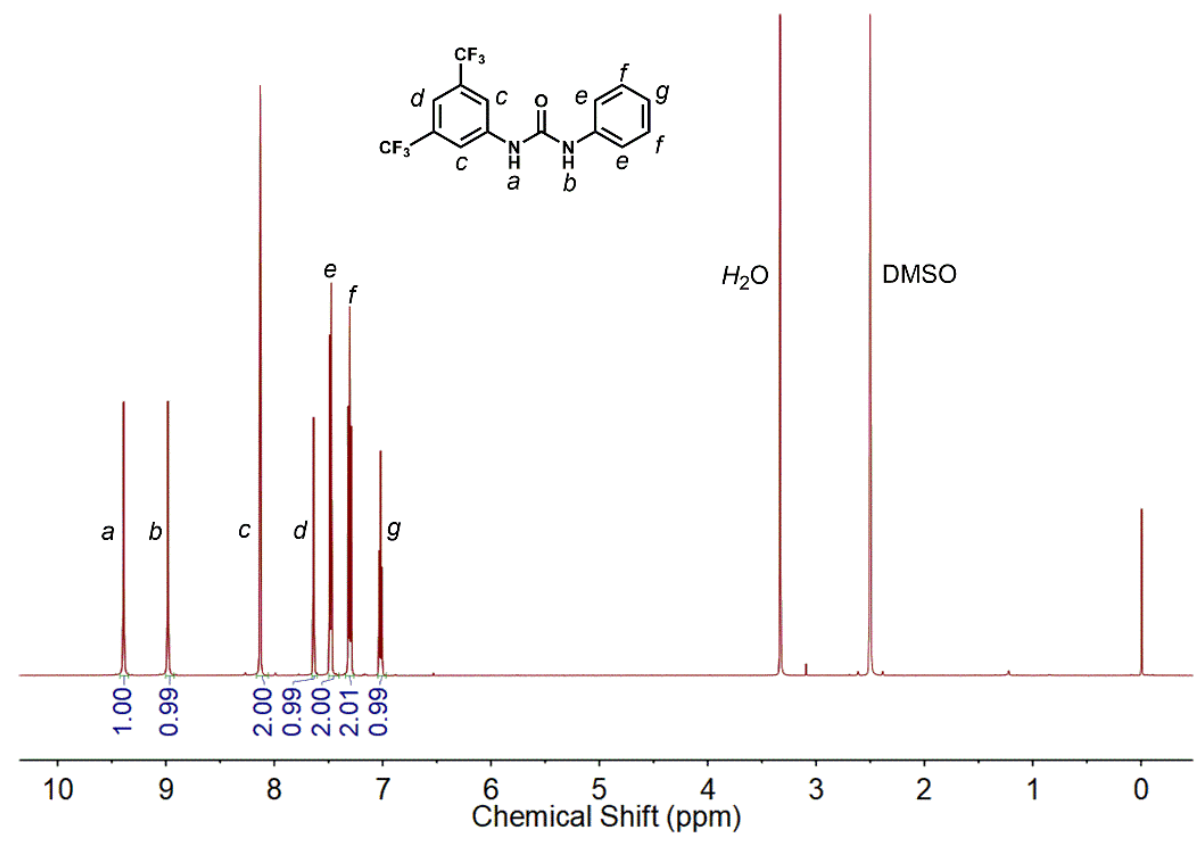

Figure S2. ${ }^{1} \mathrm{H}$ NMR (DMSO-d $)$ of U2: $\delta 9.53(a, 1 \mathrm{H}, \mathrm{s}), 9.38(b, 1 \mathrm{H}, \mathrm{s}), 8.15(c, 2 \mathrm{H}, \mathrm{s}), 8.01$ $(d, 1 \mathrm{H}, \mathrm{s}), 7.68(e, 2 \mathrm{H}, \mathrm{d}), 7.54(f, 2 \mathrm{H}, \mathrm{t}), 7.37(g, 1 \mathrm{H}, \mathrm{t})$. 

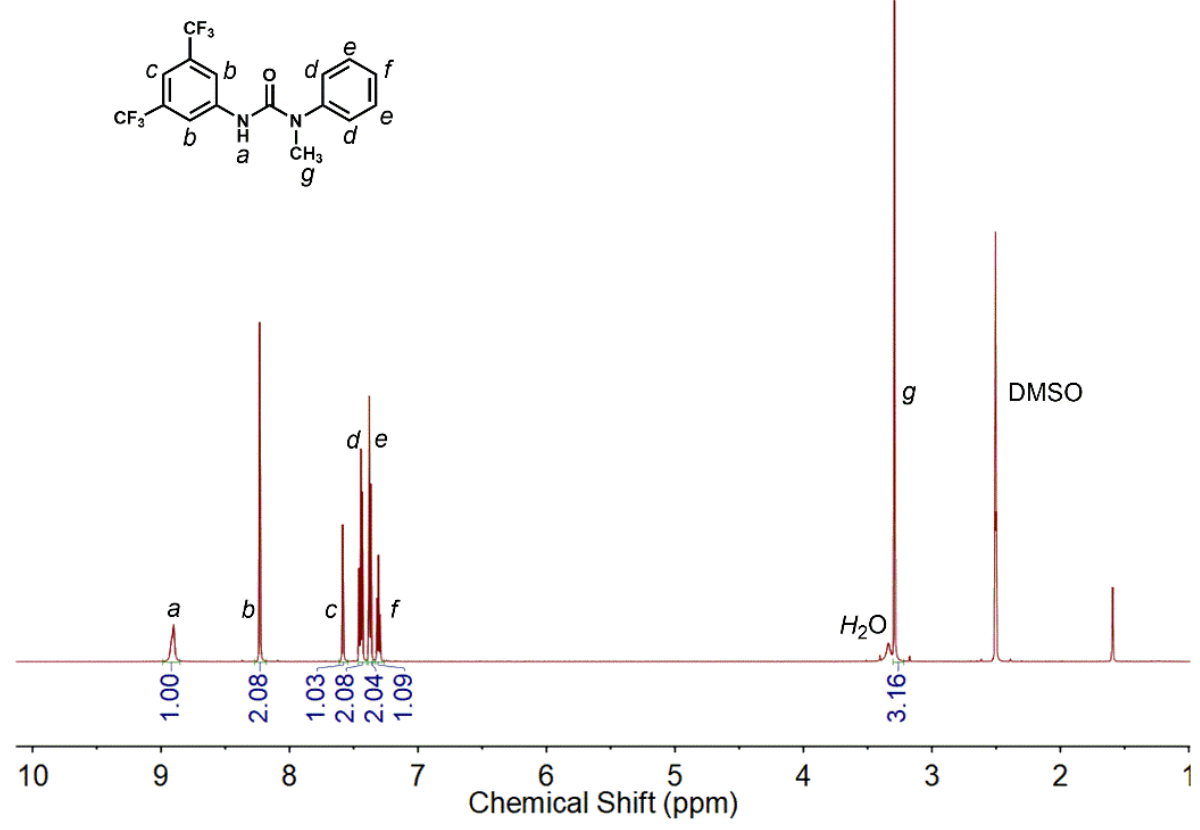

Figure S3. ${ }^{1} \mathrm{H}$ NMR (DMSO- $\left.d_{6}\right)$ of U3: $\delta 8.90(a, 1 \mathrm{H}, \mathrm{s}), 8.23(b, 2 \mathrm{H}, \mathrm{s}), 7.59(c, 1 \mathrm{H}, \mathrm{s}), 7.45$ $(d, 2 \mathrm{H}, \mathrm{d}), 7.38(e, 2 \mathrm{H}, \mathrm{t}), 7.31(f, 1 \mathrm{H}, \mathrm{t}), 3.29(g, 3 \mathrm{H}, \mathrm{s})$.

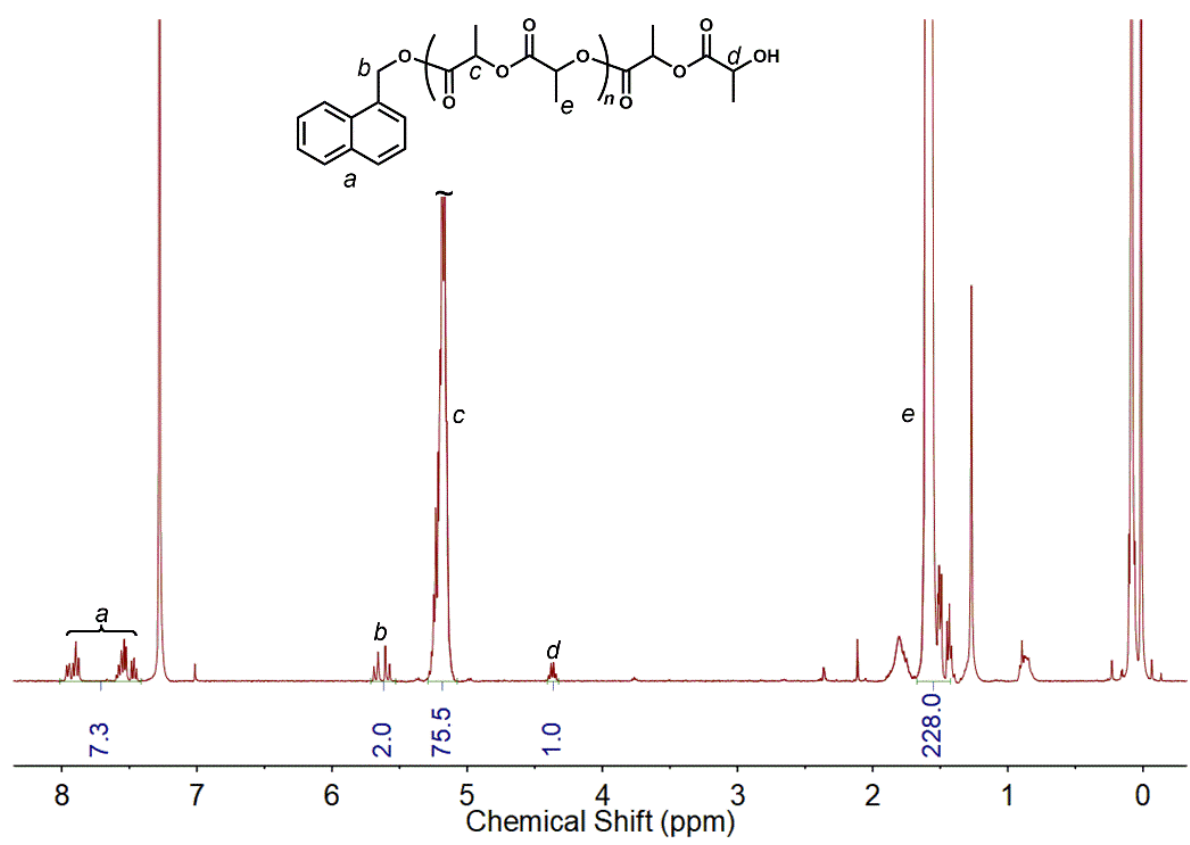

Figure S4. ${ }^{1} \mathrm{H}$ NMR spectrum of a short PLA synthesized with UA1 as the catalyst and NtA as the initiator (isolated product of U1LA1 in Table 1). 


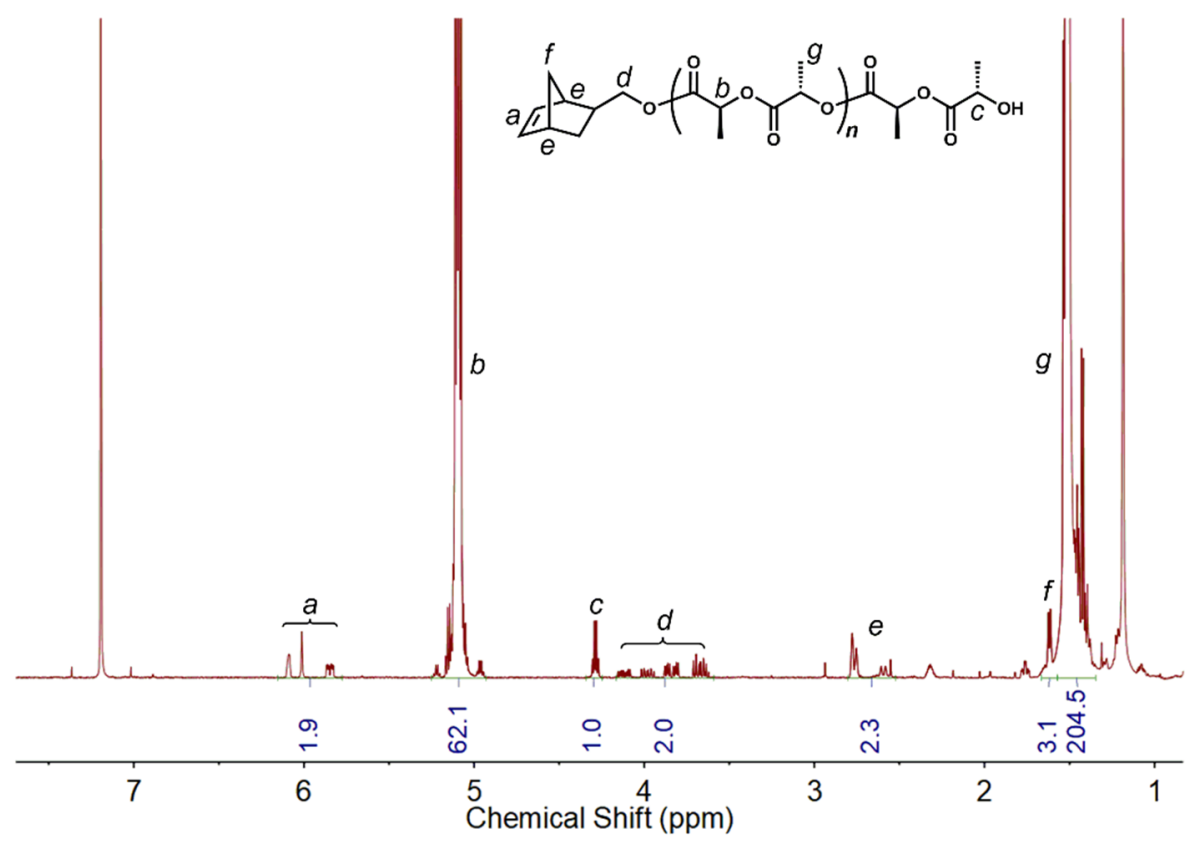

Figure S5. ${ }^{1} \mathrm{H}$ NMR spectrum of a short PLLA synthesized with UA1 as the catalyst and $\mathrm{NbA}$ as the initiator (isolated product of U1LLA1 in Table 1).

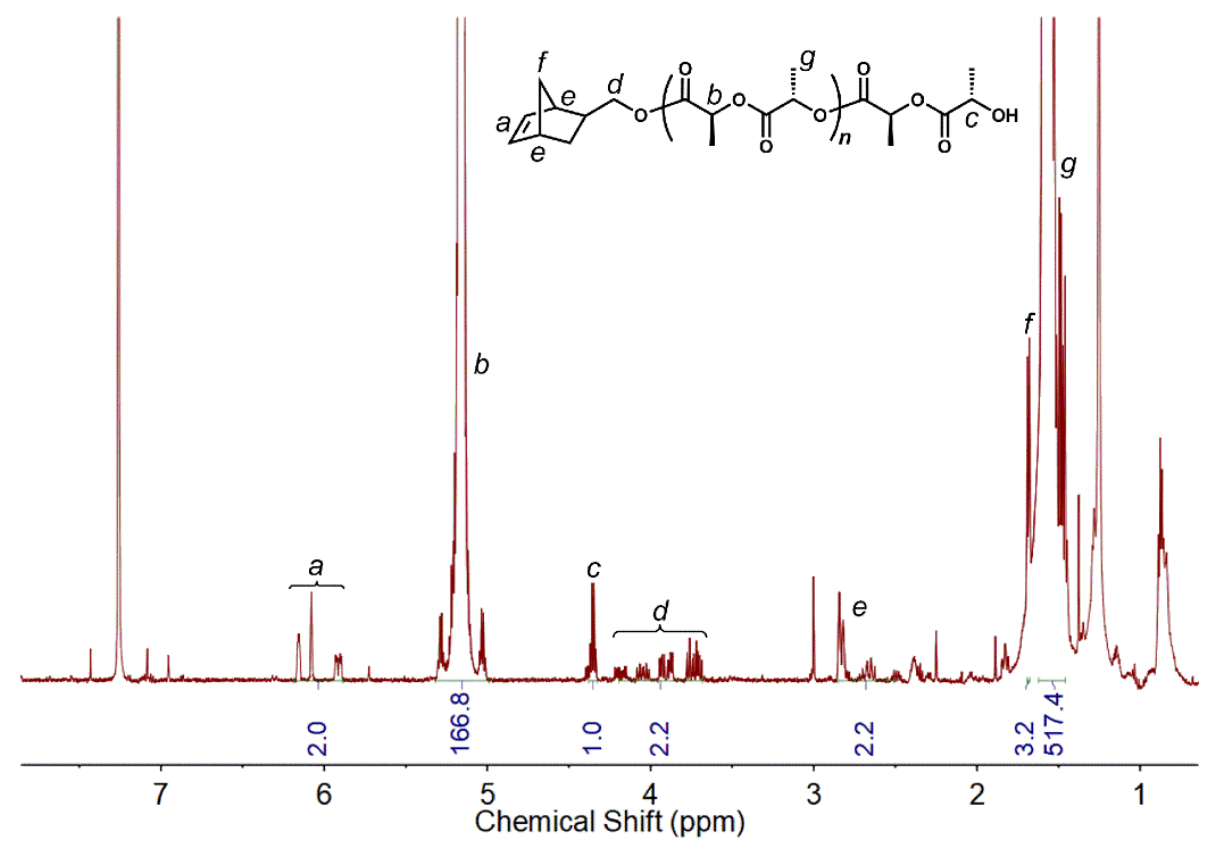

Figure S6. ${ }^{1} \mathrm{H}$ NMR spectrum of a PLLA synthesized with UA1 as the catalyst and NbA as the initiator (isolated product of U1LLA2 in Table 1). 


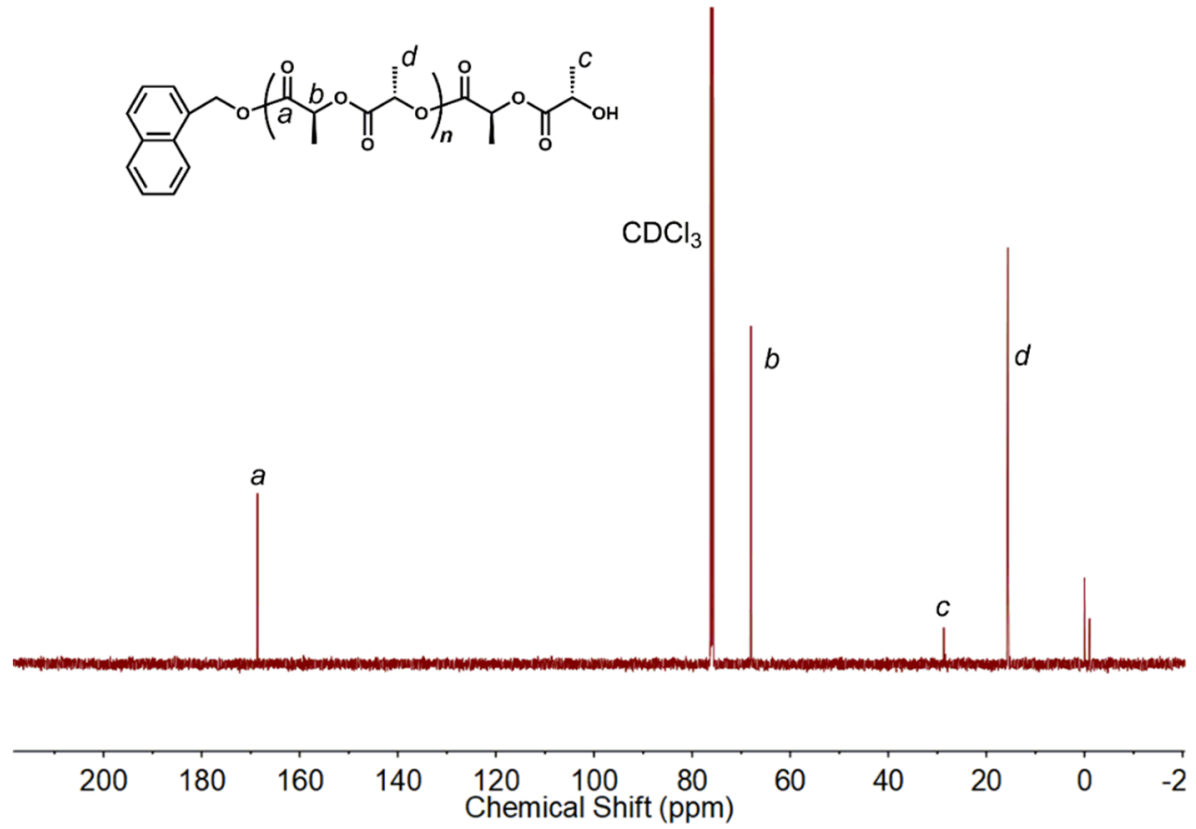

Figure S7. ${ }^{13} \mathrm{C}$ NMR spectrum of a high-molar-mass PLLA synthesized with UA1 as the catalyst and NtA as the initiator (isolated product of U1LLA5 in Table 1). 


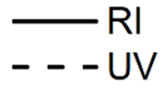

(a)

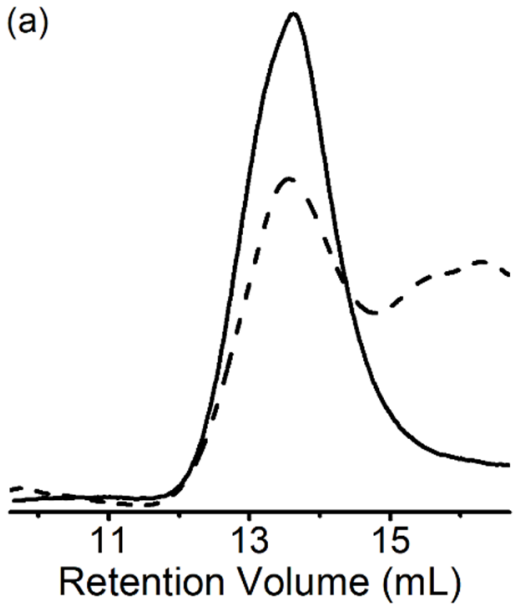

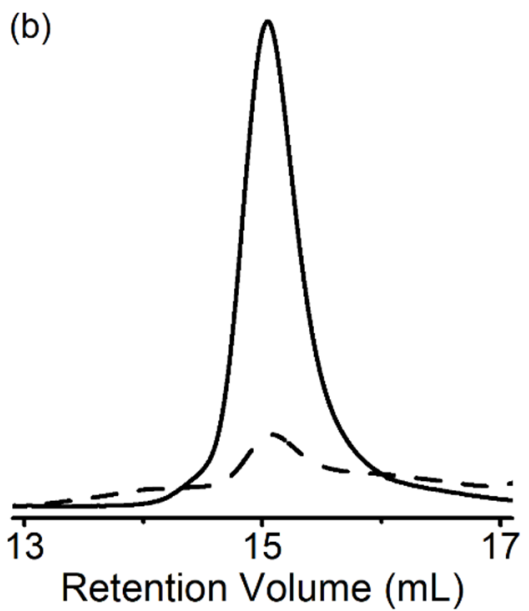

Figure S8. SEC traces of PLLAs synthesized with UA1 as the catalyst (reaction time $=1$ min). (a) No hydroxy initiator added ([LLA $]_{0} /[\mathrm{UA} 1]=100 / 1$ ). (b) $\mathrm{NbA}$ added as the initiator $\left([\mathrm{LLA}]_{0} /[\mathrm{OH}] /[\mathrm{UA} 1]=100 / 1 / 0.2\right.$; U1LLA2 in Table 1$)$. The heights of RI and UV peaks are normalized by the maximum of RI responses.

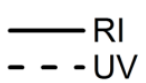

$1 \mathrm{~min}$

conv. $=99 \%$

$M_{\mathrm{n}}=147.9 \mathrm{~kg} \mathrm{~mol}^{-1}$

$\Theta_{\mathrm{M}}=1.73$
$1 \mathrm{~h}$

conv. $=99 \%$

$M_{\mathrm{n}}=70.6 \mathrm{~kg} \mathrm{~mol}^{-1}$

$\Theta_{M}=2.1$

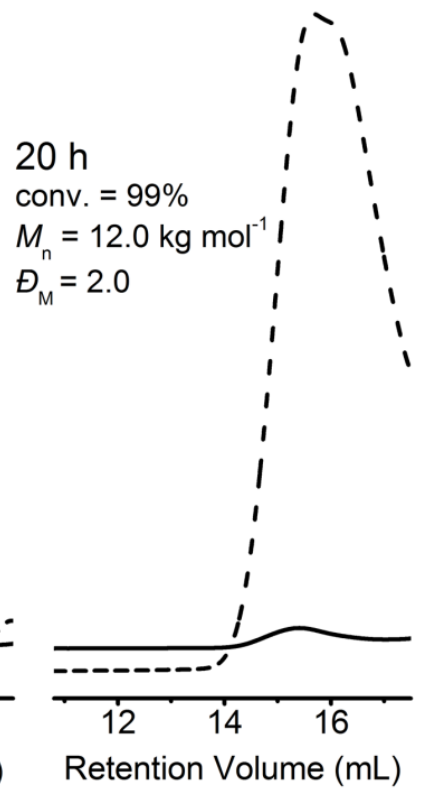

Figure S9. SEC traces of the product of ROP of LLA catalyzed by UA1 in the absence of an added initiator at different reaction times $\left([\mathrm{LLA}]_{0} /[\mathrm{UA} 1]=100 / 1\right)$. The heights of RI and UV peaks are normalized by the maximum of RI responses. 
(a)

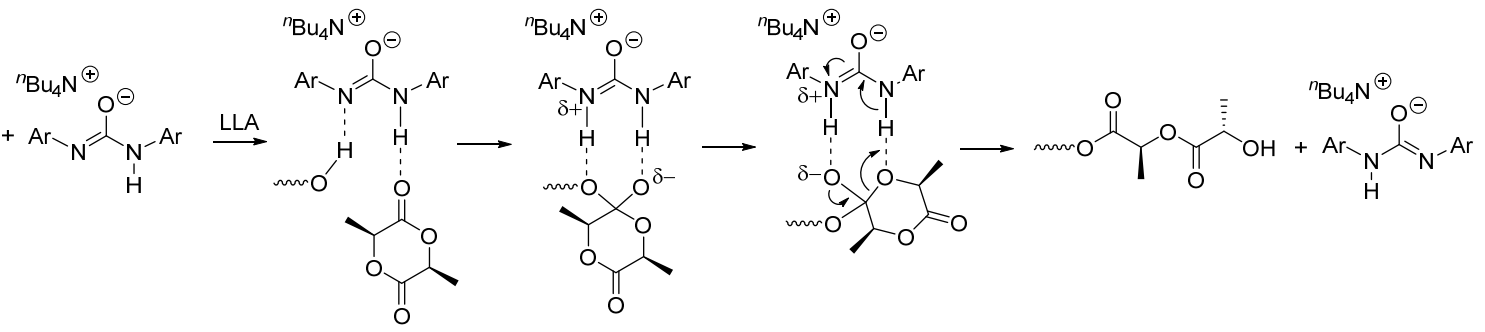

(b)

(c)
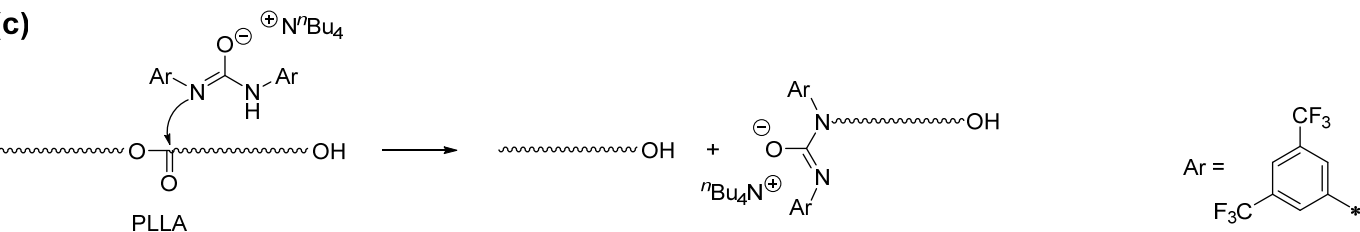

Scheme S1. Illustration of the plausible mechanistic aspects of ROP of LLA catalyzed by UA1. (a) Bifunctional monomer-hydroxyl dual activation facilitating the ring opening of LLA. (b) ROP triggered by direct nucleophilic attack of urea anion on LLA. (c) Reduction of molar mass of PLLA at extended reaction time because of nucleophilic attack of unreacted urea anion on PLLA.

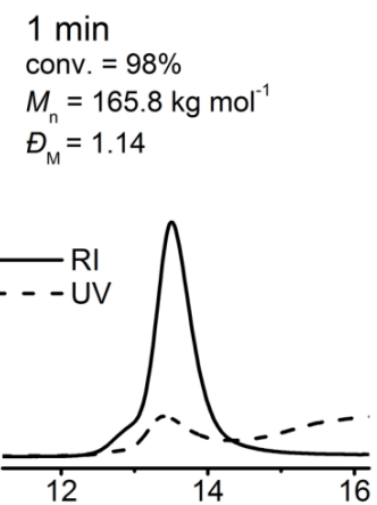

Retention Volume (mL)
$1 \mathrm{~h}$

conv. $=98 \%$

$M_{\mathrm{n}}=151.9 \mathrm{~kg} \mathrm{~mol}^{-1}$

$\oplus_{\mathrm{M}}=1.42$

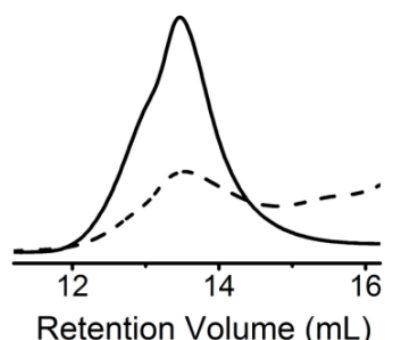

$20 \mathrm{~h}$

conv. $=98 \%$

$M_{\mathrm{n}}=106.5 \mathrm{~kg} \mathrm{~mol}^{-1}$

$\Theta_{\mathrm{M}}=2.10$

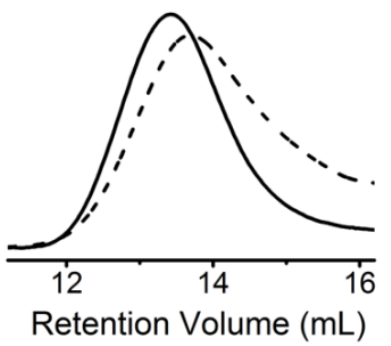

Figure S10. SEC traces of the product of ROP of LLA catalyzed by UA1 in the absence of an added initiator at different reaction times $\left([\mathrm{LLA}]_{0} /[\mathrm{UA} 1]=500 / 1\right)$. The heights of RI and UV peaks are normalized by the maximum of RI responses. 
Table S1. Synthesis of PLLA-Based Block Copolymers Using UA1.

\begin{tabular}{|c|c|c|c|c|c|c|c|c|}
\hline entry & init. & {$[\mathrm{M}]_{0} /[\mathrm{OH}] /[\mathrm{UA} 1]^{a}$} & time & $\begin{array}{l}\text { conv. } \\
(\%)\end{array}$ & $\begin{array}{l}M_{\mathrm{n}, \mathrm{th}}{ }^{b} \\
\left(\mathrm{~kg} \mathrm{~mol}^{-1}\right)\end{array}$ & $\begin{array}{l}M_{\mathrm{n}, \mathrm{SEC}}{ }^{c} \\
\left(\mathrm{~kg} \mathrm{~mol}^{-1}\right)\end{array}$ & $\bigoplus_{\mathrm{M}^{c}}$ & $\begin{array}{l}M_{\mathrm{n}, \mathrm{NMR}^{d}} \\
\left(\mathrm{~kg} \mathrm{~mol}^{-1}\right)\end{array}$ \\
\hline $\mathrm{U} 1 \mathrm{VL}^{e}$ & $\mathrm{NbA}$ & $100 / 1 / 0.2$ & $105 \mathrm{~min}$ & 90 & 9.0 & 14.4 & 1.13 & \\
\hline U1VL-LLA $^{e}$ & $\mathrm{NbA}$ & $100 / 1 / 0.2$ & $5 \mathrm{~min}$ & 84 & 21.1 & 28.1 & 1.15 & 21.8 \\
\hline $\mathrm{U} 1 \mathrm{CL}^{e}$ & $\mathrm{TP}$ & $40 / 1 / 0.2$ & $2.5 \mathrm{~h}$ & 92 & 12.6 & 21.4 & 1.16 & \\
\hline $\mathrm{U} \mathrm{CL}-\mathrm{LLA}^{e}$ & $\mathrm{TP}$ & $40 / 1 / 0.2$ & $1 \mathrm{~min}$ & 97 & 29.4 & 45.3 & 1.14 & 30.5 \\
\hline U1LLA9 & PS-OH & $139 / 1 / 0.2$ & $5 \mathrm{~min}$ & 97 & 30.0 & 41.9 & 1.07 & 26.2 \\
\hline
\end{tabular}

${ }^{a}$ Molar feed ratio of monomer, hydroxyl, and UA1. ${ }^{b}$ Theoretical number-average molar mass calculated from $[\mathrm{M}]_{0} /[$ initiator $]$ and monomer conversion. ${ }^{c}$ Apparent number-average molar mass and molar mass distribution obtained from SEC analysis of the crude product. ${ }^{d}$ Number-average molar mass calculated from ${ }^{1} \mathrm{H}$ NMR spectrum of the isolated product. ${ }^{e}$ Block copolymerization by sequential monomer addition, performed first in THF for VL/CL and then in a mixture of THF and DCM for LLA. 

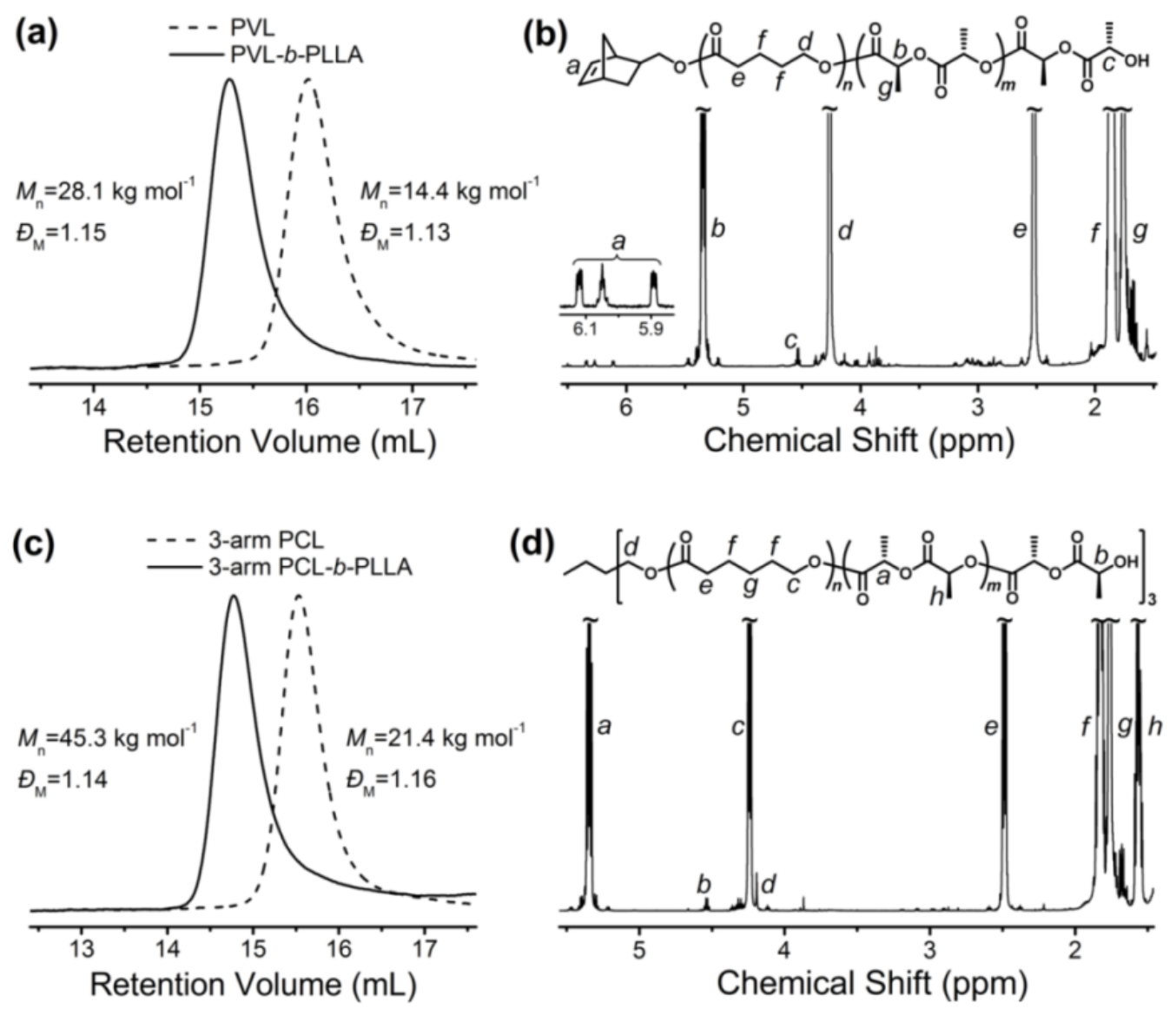

Figure S11. (a) SEC traces of a PVL precursor and a linear PVL- $b$-PLLA diblock copolyester synthesized with UA1 as the catalyst (U1VL and U1VL-LLA in Table S1). (b) ${ }^{1} \mathrm{H}$ NMR spectrum of the isolated PVL- $b$-PLLA. (c) SEC traces of a 3-arm PCL precursor and a (PCL-b-PLLA) 3 3-arm star-shaped block copolyester synthesized with UA1 as the catalyst (U1CL and U1CL-LLA in Table S1). (d) ${ }^{1} \mathrm{H}$ NMR spectrum of the isolated (PCL- $b$-PLLA) 3. 


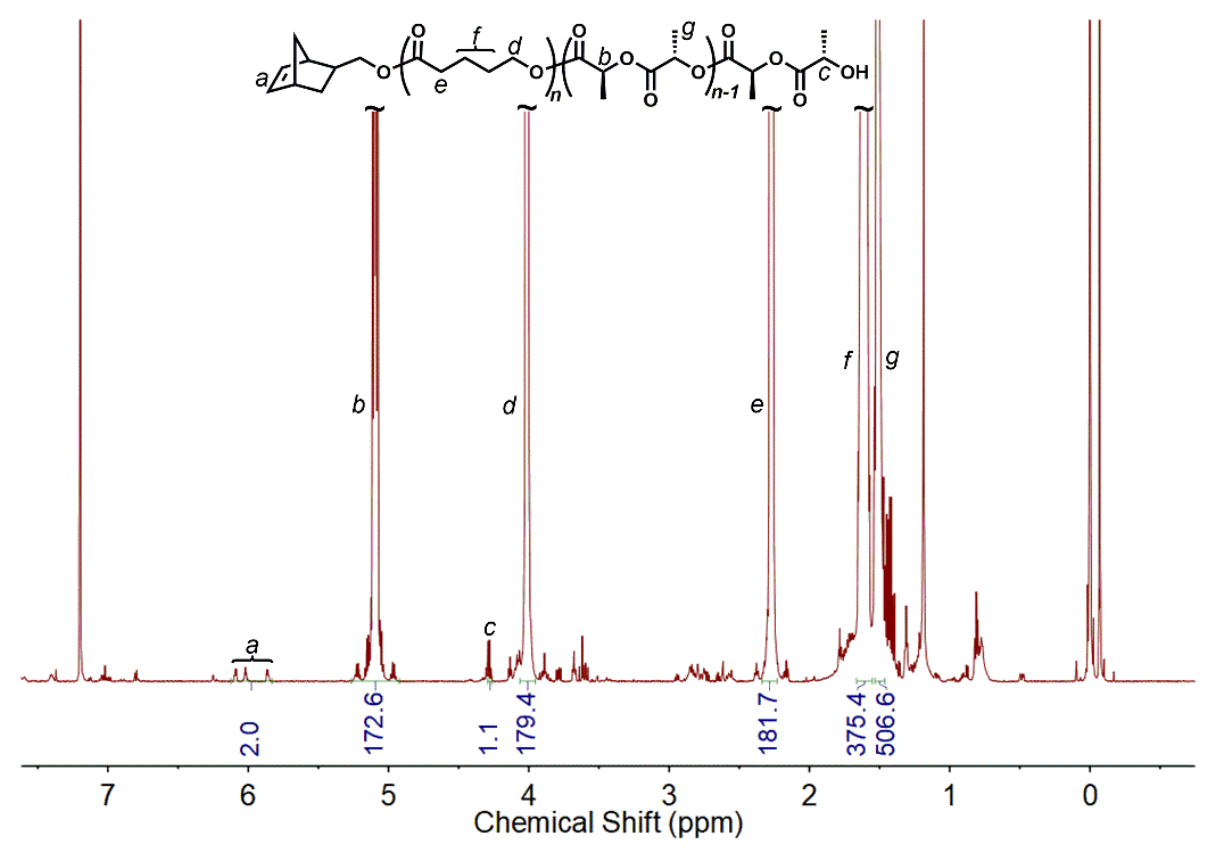

Figure S12. ${ }^{1} \mathrm{H}$ NMR spectrum of a PVL- $b$-PLLA diblock copolymer synthesized with UA1 as the catalyst and $\mathrm{NbA}$ as the initiator (isolated product of U1VL-LLA in Table S1).

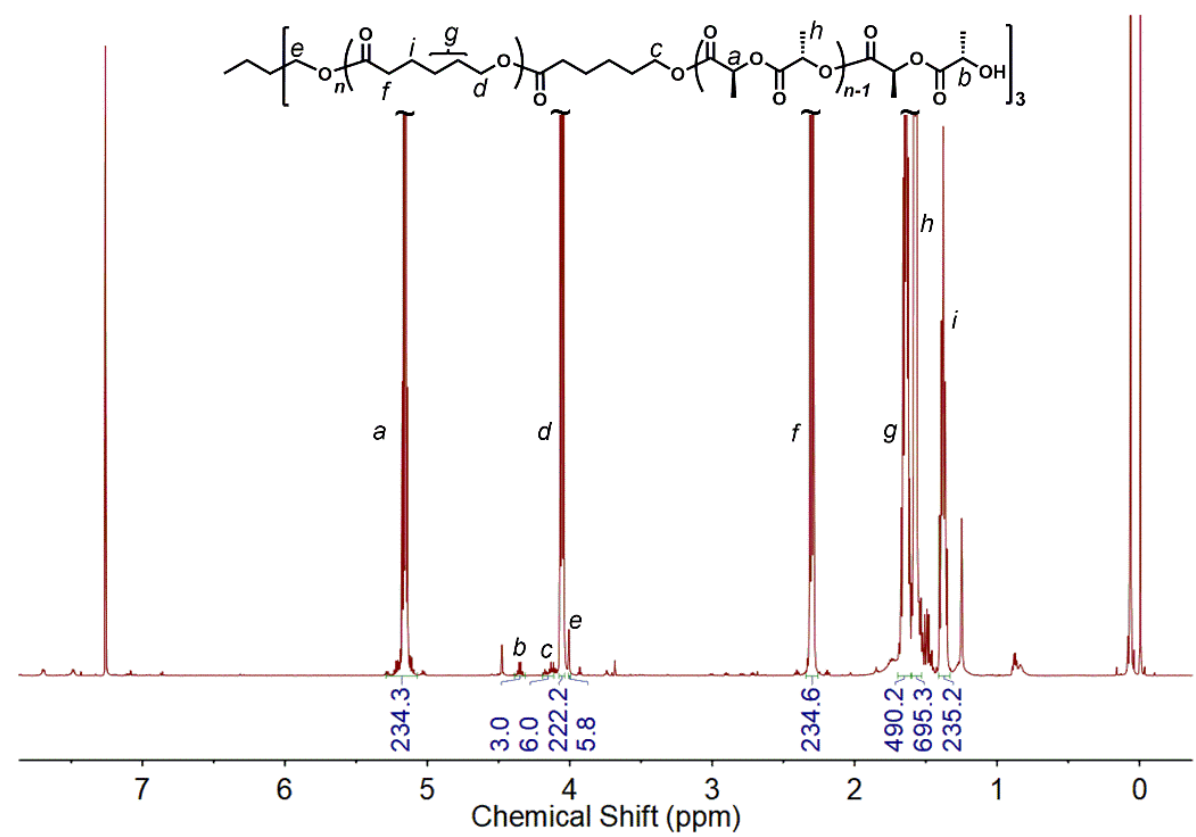

Figure S13. ${ }^{1} \mathrm{H}$ NMR spectrum of a (PCL- $b$-PLLA) 3 3-arm star-shaped block copolyester with UA1 as the catalyst and TP as the initiator (isolated product of U1CL-LLA in Table S1). 

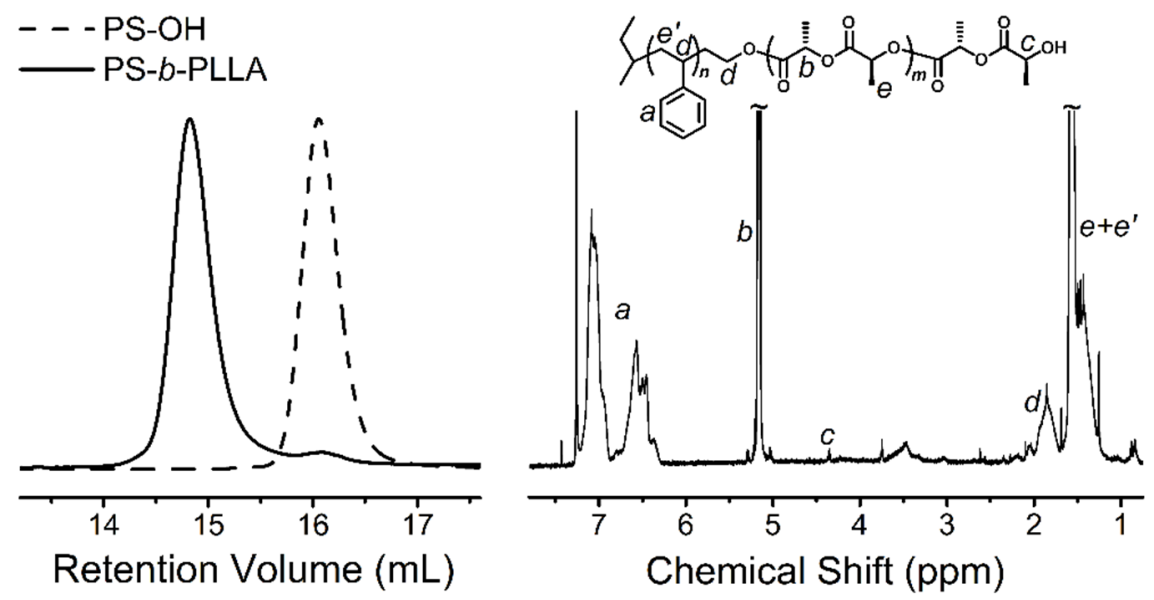

Figure S14. SEC trace (RI signal; crude product) and ${ }^{1} \mathrm{H}$ NMR spectrum (isolated product) of a PS- $b$-PLLA diblock copolymer synthesized with UA1 as the catalyst and hydroxyl-terminated polystyrene (PS-OH) as the initiator (U1LLA9 in Table S1). 